\title{
Sobre Trote, Vampiros e Relacionamento Humano nas Escolas Médicas
}

\section{About Hazing, Vampires and Relationships at the Medical School}

Maria Cristina Pereira Lima

\section{PALAVRAS-CHAVE \\ - Educação Médica. \\ - Ética Institucional. \\ - Bullying.}

\section{KEYWORDS}

- Medical Education.

- Institutional Ethics.

- Bullying.
Recebido em: 25/11/2011

Reencaminhado em: 23/03/2012

Aprovado em: 21/05/2012

REVISTA BRASILEIRA DE EDUCAÇÃO MÉDICA

\section{RESUMO}

Os relacionamentos dos estudantes entre si e destes com seus professores podem se tornar difíceis em diferentes momentos. O ingresso na universidade parece ser um período especialmente tenso em função dos trotes sofridos nesta fase da vida acadêmica. Este estudo apresenta uma revisão da literatura a respeito do trote, em especial aquele realizado nas escolas médicas, tentando identificar as características ritualísticas e os fatores mantenedores deste. Paralelamente, constrói uma metáfora com o mito do vampiro, propondo esta lenda como um paradigma para compreender as relações humanas nas faculdades de Medicina. São discutidas as características comuns entre vampiros e vítimas, encontradas no mito e nas inter-relações presentes nas escolas médicas, abordando-se possíveis estratégias de manejo.

\begin{abstract}
The students' relationships with one another and their teachers can become difficult at different times. However, entrance into the university seems to be a particularly tense moment, due to the hazing suffered this stage of their academic lives. This study presents a review of the literature on the hazing, especially that have happen in medical schools, trying to identify the characteristics and maintaining factors of those ritual. In parallel, constructs a metaphor of the vampire myth, proposing this legend as a paradigm for understanding the human relationships in the medical schools. The common characteristics between vampires and victims, found in myth, and these interrelationships are discussed in medical schools, approaching at possible management strategies.
\end{abstract}




\section{SOBRE O TROTE}

Madrugada quando levantei e me preparei com minha melhor roupa... Temeroso fui me chegando... Era a eterna estupidez do trote... Nenhum socorro possível... A escola estava entregue à malta dos veteranos desencadeada contra o rebanho indefeso dos calouros... Cheguei em casa todo dolorido dos encontrões e dos trancos, chorando não de dor mas chorando por causa de meu único terno decente... fiquei em casa o dia todo, triste, triste. ${ }^{1}$ (p. 314-317)

Nascido na Europa, o advento do trote coincide com o ingresso da burguesia nas universidades, sendo, na ocasião, largamente aplicado pelos nobres, até então o único segmento da sociedade a frequentar a academia ${ }^{2}$. Embora esteja proibido por leis específicas em alguns dos Estados do País e possa inclusive ser enquadrado em uma série de artigos do código civil, sua extinção tem parecido impossível. Lamentavelmente, já ocorreram mortes durante situações que caracterizaram trote, para desespero de famílias, calouros e professores ${ }^{3}$.

Para alguns, autores o trote pode ser encarado como um ritual de entrada ou iniciação no novo grupo ao qual o calouro pretende se integrar. Segundo Van Gennep ${ }^{4}$, os rituais seriam formas de um sujeito, inserido em determinada cultura, realizar a passagem de determinada condição a outra, havendo três modalidades distintas de rituais: os de separação, os de agregação e, por fim, os de iniciação ou margem. Os ritos de iniciação são aqueles nos quais os sujeitos que são incorporados a determinado grupo social recebem instruções especiais a fim de possibilitar sua integração ao grupo; como mencionado, o trote se encaixaria neste último grupo.

Apesar de seu possível papel integrador, o problema em torno do trote é que ele guarda, ainda hoje, as reminiscências do uso que dele faziam os nobres na Idade Média. Tendo a função de destacar a diferença entre os ingressantes e os veteranos e não de integrá-los, o trote seria assim um rito de iniciação "às avessas"2. Ao invés de introduzir o estudante em uma instituição que preza a democracia e a defesa dos ideais humanitários, o trote transmitiria - ou poderia transmitir — o ideário de uma instituição hierárquica e autoritária ${ }^{2}$. Esta ideia poderia levar à conclusão equivocada de que os trotes deveriam ser proibidos. No entanto, como dito acima, ao menos no que diz respeito aos aspectos legais, eles já o são. Assim, mais do que propor ou reforçar a proibição, seria necessário compreender o papel que exercem nas instituições de ensino para pensar em possíveis intervenções.

Sobre os rituais, de modo geral, sabe-se que têm uma função social nas comunidades em que se inserem - função que precisa ser identificada. Em ampla revisão sobre os rituais, Rodolpho ${ }^{5}$ afirma que os ritos têm uma função organizadora nas sociedades, pois, uma vez que se caracterizam pela repetição de determinadas atividades e atos, os rituais conferem segurança aos elementos desta comunidade. Segundo a autora: “[...] através da repetição e da formalidade, elaboradas e determinadas pelos grupos sociais, os rituais demonstram a ordem e a promessa de continuidade destes mesmos grupos" (p.140).

Em face de eventos desagradáveis e muitas vezes trágicos, calouros frequentemente afirmam que não pretendem repetir os comportamentos dos quais foram vítimas quando vierem a se tornar veteranos. No entanto, o comportamento se mantém, como pode ser fartamente observado na imprensa leiga a cada início de ano. Em fevereiro de 2011, um jornal publicado em São Paulo, em caderno dedicado especialmente ao vestibular, divulgou histórias de violências ocorridas com calouros, bem como os telefones para denúncias no caso de novos alunos enfrentarem trotes em suas escolas ${ }^{6}$.

Se as experiências de trote são vividas muitas vezes como desagradáveis e violentas, por que então se mantêm ano após ano, apesar das medidas legais adotadas? Algumas hipóteses têm sido propostas para o fenômeno da repetição e manutenção do trote. Uma primeira parece estar relacionada à natureza dos rituais de iniciação. Segundo Zempléni (apud Rodolpho ${ }^{5}$ ), os ritos de iniciação têm uma característica que os distingue dos demais, que é a autorreferencialidade. Em breves palavras, isto significa que o "iniciado" só se torna parte do grupo quando ele próprio participar da iniciação de outrem. Não é à toa que o ritual de iniciação é também chamado de "ritual de margem", pois estabelece um antagonismo entre "dentro" e "fora", pertencendo a este último aqueles que estão desejosos de ingressar no grupo. Assim, apenas após submeter o calouro do ano seguinte ao trote, o iniciado se tornará parte do grupo de estudantes/veteranos - o que garante a hierarquia e mantém um círculo vicioso que tende à manutenção deste ritual.

Em extenso ensaio sobre o trote, Vasconcelos ${ }^{2}$ defende que talvez haja na repetição do trote o desejo de vingança, numa busca mágica e irracional de reparar o que ocorreu repetindo o ato violento sobre outrem. Para poder repetir a ação, mas não se identificar com aquele que sofre o trote, o veterano o desumaniza, transforma-o em "coisa", chamando-o de "bixo". Embora na posição de veterano haja o esforço para desumanizar e não se identificar com o calouro, este último deseja se tornar veterano e se identifica intensamente com este ${ }^{2}$. Para se ver livre do trote, o calouro projeta sua liberdade na transformação em veterano: 
$\mathrm{Na}$ realidade, o oprimido se aliena de si no ser do opressor. Duas formas de alienação: a aceitação da ação do opressor e, a posteriori, a reprodução da opressão, quando recusa sua realização por meio da libertação para querer realizar-se também como opressor² (p. 26).

Com base na experiência acadêmica e em denúncias feitas por estudantes, Akerman et al. ${ }^{7}$ reforçam a ideia de que o trote serve mais para manter a hierarquia existente nas escolas médicas do que para integrar os iniciantes. Entre os vários aspectos levantados pelos autores, chama a atenção o caráter autoritário de que se reveste a realização do trote:

1. A recepção aos calouros tem como meta principal entre os estudantes que o recebem fortalecer o "espírito de corpo", fazendo-o aceitar as regras vigentes, predominando aquela relativa à hierarquia entre calouro e veterano; 2 . Este intuito, muitas vezes, é relacionado pelos estudantes à mesma hierarquia existente entre os médicos, e entre professores e alunos; 3 . Para ser parte, o aluno tem que "baixar a bola", uma vez que ele "se acha" por ter passado em um curso tão difícil. Manter-se de cabeça baixa e ser chamado de calouro é parte do ritual ${ }^{7}$ (p. 627)

Os autores observam também que algumas atividades são justificadas, no caso dos estudantes de Medicina, pela necessidade de o futuro médico se mostrar capaz de aguentar sofrimento. Para ser médico, tem que suportar, tem que ser "durão". No estudo já citado de Vasconcelos², há menção de que os cursos mais concorridos apresentariam os trotes mais violentos. Em sociedades primitivas, os ritos de passagem são também constituídos de atividades físicas intensas e muitas vezes dolorosas ${ }^{8}$. Aparentemente, além de testarem a resistência dos sujeitos, estas atividades serviriam para reforçar a hierarquia do grupo ${ }^{8}$. Akerman et al. ${ }^{7}$ destacam ainda que, embora nem todos cometam atos violentos, há uma possível conivência do grupo, porque muitos assistem e não se manifestam. Possivelmente, o silêncio daqueles que "apenas" assistem seria uma manifestação da força do grupo em manter seu status quo. Do ponto de vista do calouro, não participar do trote, ou, pior ainda, denunciá-lo poderá implicar sanções, sendo a exclusão do grupo a mais temida entre elas ${ }^{7,9}$. Como consequência, instala-se o silêncio sobre o trote.

5. Nem todos os calouros se submetem, mas isso tem um preço: não conseguem ser parte do "corpo"; 6. Não são muitos os estudantes que cometem atos violentos e abusos verbais, físicos e psicológicos, mas são muitos os estudantes que se omitem, num silêncio cúmplice e numa atmosfera de "reino do medo"; 7. Alguns professores consideram naturais estes episódios, recordando sua época de estudante; 8 . Intimidações, abusos e assimetrias de poder entre estudantes não se restringem ao período de recepção ao calouro, conhecido como "trote"; são atos que persistem ao longo do ano, nos fazendo imaginar que o bullying - atitudes agressivas, intencionais e repetidas, que ocorrem sem motivação evidente e adotadas por um ou mais estudantes contra outro(s), causando dor e angústia, e executadas numa relação desigual de poder -, descrito e relatado no ensino fundamental e médio, está presente também no ensino universitário ${ }^{7}$. (p. 627-628).

Partindo de uma análise de discursos de professores e alunos de uma escola médica, Villaça e Palácios ${ }^{9}$ identificaram uma série de situações de violência ocorridas por ocasião do trote e destacaram que as mesmas são percebidas pelos estudantes como corriqueiras, circunstanciais, individuais e até certo ponto esperadas, naturalizadas. Contudo, quando o veterano recorda sua própria condição de calouro, retoma o desconforto que sentira e os sentimentos de raiva e impotência experimentados quando da entrada na faculdade?

\section{SOBRE O ABUSO NAS ESCOLAS MÉDICAS}

A ideia da possível existência de abuso nas escolas médicas foi introduzida por Silver ${ }^{10}$ em 1982, quando o autor comparou a transformação que os jovens alunos de Medicina sofrem ao longo do curso com aquela que ocorre em crianças vítimas das mais diversas formas de violência. Desde então, a questão vem sendo estudada em escolas médicas de diversos países, mostrando-se um problema bem mais prevalente do que se supunha até então.

Um estudo desenvolvido nos Estados Unidos e que envolveu 16 escolas médicas observou que $42 \%$ dos estudantes referiam já terem sido molestados, enquanto $84 \%$ referiam terem sido de algum modo depreciados durante o curso médi$\mathrm{CO}^{11}$. Os autores não observaram diferenças em relação a gênero ou raça entre os sujeitos que referiram tais problemas. No entanto, o grupo que referia ter sido molestado ou depreciado mostrou maior probabilidade de apresentar estresse, sintomas depressivos, ideação suicida e uso abusivo de álcool, entre ou$\operatorname{tros}^{10}$. Uma pesquisa desenvolvida no Japão identificou que 85,5\% dos estudantes de Medicina foram vítimas de abuso ao longo do internato. O tipo de abuso mais frequente foi o verbal, e todas as formas de abuso se mostraram mais prevalentes entre as mulheres ${ }^{12}$. 
Um estudo realizado pela British Medical Association, citado por Palácios e Rego ${ }^{13}$, observou que um terço dos sujeitos referia ter sofrido bullying e que um em cada quatro relatava ter sido vitimado por um médico(a), enquanto um sexto referia ter sido vítima de maus-tratos por enfermeiro(a). As formas de maus-tratos variaram desde discriminações raciais e sexuais a humilhações na frente de pacientes e colegas. Entrevistando estudantes de Medicina, $\operatorname{Rego}{ }^{14}$ observou que a prática de maus-tratos por parte dos professores parece frequente. Atitudes negativas dos professores, além de não serem pedagógicas por não melhorarem o aprendizado, podem ainda ser deletérias para a saúde dos estudantes ${ }^{15}$.

Embora reconhecido como fenômeno "internacional"16, no Brasil o uso do termo "abuso" nas escolas médicas surgiu na literatura apenas recentemente ${ }^{17}$. Apesar disto, situações de humilhações, maus-tratos e discriminação de acadêmicos por preceptores e professores foram relatadas previamente ${ }^{18}$. Em um estudo exploratório que procura identificar situações desagradáveis sofridas por alunos de três cursos de Medicina, Azevedo et al..$^{18}$ observaram que $76 \%$ dos estudantes referiram ter se sentido depreciados de alguma forma, $42 \%$ relataram sofrer severas críticas e monitorização persistente em demasia, $40 \%$ sofreram humilhações perante os colegas e cerca de um quarto relatou ameaças verbais ou não verbais de seus professores. Este achado coincide com o obtido por Uhari et $a l .{ }^{16}$, no qual os autores observaram que três em cada quatro estudantes finlandeses reportaram algum tipo de maus-tratos sofridos durante sua formação médica.

Ao comparar a situação vivida pelo estudante de Medicina com aquela experimentada pela criança que sofre relações abusivas, Silver ${ }^{10}$ destacou algumas semelhanças. Em ambas as situações — crianças abusadas e alunos abusados -, há uma proibição não explícita de discutir o problema, há uma interdição. Outro aspecto que parece similar a ambas é o círculo vicioso de violência que se observa no funcionamento destas relações. Embora ainda haja muita controvérsia a respeito, sujeitos que cometeram violências contra crianças têm maiores chances de terem sido vítimas de violências ${ }^{19}$. Cukier ${ }^{20}$ conta que, em sua prática psicoterápica, repete-se a cena de uma criança que sofre ou assiste a uma situação de violência, aqui entendida como o abuso de poder de um adulto sobre a criança, podendo este ser físico ou não. Ainda segundo a autora, um fato intrigante é que esta cena é frequentemente narrada por um adulto bem-sucedido profissionalmente, mas com dificuldades relacionais e afetivas intensas, tendo se tornado, ele próprio, o adulto abusador de outrora.

Em um ensaio sobre abuso na infância, Bütz ${ }^{21}$ propõe uma comparação deste com o mito do vampiro, particularmente no que diz respeito à reprodutibilidade e à manutenção do circulo vicioso de violência. Para o autor, o fascínio que se mantém em torno deste mito ao longo dos séculos pode ser explicado pela sua possível associação com as relações abusivas vividas em especial por crianças, em diferentes momentos da história ocidental. Para que se possa explorar a mesma metáfora, agora entre vampiros e abuso nas escolas médicas, é necessário rever, ainda que brevemente, o mito em sua descrição clássica.

\section{SOBRE O MITO DO VAMPIRO}

O mito do vampiro é um dos mais antigos na cultura ocidental ${ }^{22}$. A versão mais conhecida do mito, concebido após anos de estudo do autor sobre o tema, é Drácula, do escritor Bram Stocker. De acordo com Lecouteux ${ }^{23}$, este romance teria tido a função de organizar diversos aspectos do mito, presentes na cultura europeia, construindo uma espécie de "saber vampirológico". É deste romance do escritor irlandês que saíram informações sobre o mito do vampiro, como, por exemplo, a impossibilidade de adentrar um recinto se não for convidado previamente ou as formas de evitar que alguém se transforme em vampiro ${ }^{23}$.

No passado, quando diversas doenças eram ainda desconhecidas em termos de sua fisiopatologia, o mito de vampiro serviu como possível explicação para sua ocorrência. Segundo Sledzik e Bellantoni ${ }^{24}$, doenças potencialmente fatais foram interpretadas como sinais de vampirismo nos séculos XVIII e XIX. Isto ocorria em função dos aspectos físicos semelhantes observados entre os doentes e os supostos seres vampirizados, como, por exemplo, o emagrecimento nos portadores de tuberculose. Quando a tuberculose ocorria em homens jovens e frequentadores da vida noturna, agregava elementos para que a crença fosse plausível. Os autores descreveram como exemplo o corpo de um sujeito com lesões ósseas compatíveis com tuberculose, cujos ossos teriam sido encontrados "embaralhados" - aparentemente, um artifício para impedir que o morto-vivo retornasse. Outras doenças, como, por exemplo, a porfiria, também foram associadas às suspeitas de vampirismo entre seus portadores ${ }^{25}$.

De acordo com La Sierra ${ }^{26}$, existem lendas semelhantes em culturas tão distantes como a babilônica, a mexicana pré-hispânica e mesmo a chinesa. Apesar das modificações que o mito do vampiro apresenta nas versões contemporâneas, chama atenção a sua persistência até os dias de hoje. Tentando elucidar a manutenção do mito, La Sierra ${ }^{26}$ propõe que talvez o mesmo se mantenha em função da atração que existe sobre o vampiro, sendo a mordida um simulacro do ato sexual em si. Outra possibilidade é que, embora temido, o vampiro seria também invejado pelo poder que supostamente existiria em sua força e imortalidade ${ }^{26}$. 
Nas lendas que o originam há ainda a ideia de que o vampiro foi inicialmente vítima de algum tipo de violência que culminou em sua morte ou na ocorrência de uma morte súbita sem explicação. Para evitar que a pessoa se tornasse um vampiro, havia alguns procedimentos a executar com o cadáver, como, por exemplo, colocar incenso nas narinas e nos olhos, colocar alho na boca e no ânus ou cortar a cabeça e colocá-la aos pés do morto ${ }^{23}$. Reforça-se assim a ideia de que o vampiro não seria, pura e simplesmente, uma representação do mal, mas, sim, alguém que, ao morder sua vitima, reproduz a violência sofrida, perpetuando um ciclo de violência.

\section{SOBRE VAMPIROS, ABUSOS E ESCOLAS MÉDICAS}

Algumas semelhanças entre o ciclo de vida do vampiro e o ciclo de violência e abusos que ocorre nas escolas médicas podem auxiliar na compreensão desta metáfora. Assim como os vampiros seduzem pelo poder que possuem — visto que são imortais - , calouros e estudantes podem também se sentir seduzidos pelo poder médico e pelo almejado controle sobre vida e morte. Além do suposto poder sobre a vida e a morte, outros aspectos têm sido identificados no desejo de ser médi$\mathrm{CO}^{27}$. Porém, no que diz respeito às relações, a expectativa não parece ser pelo saber, mas sim pela possibilidade de submeter o outro, entre outras coisas, ao trote. Uma vez que docentes e preceptores também podem se envolver em situações de maus-tratos, reforça-se a hierarquia e a ideia de que os estratos superiores da escala hierárquica teriam um poder sobre os estratos inferiores, podendo submetê-los à sua vontade.

Outra similaridade é que vampiros foram inicialmente vítimas de violências que os transformaram em tais criaturas. É plausível supor que as situações de abuso identificadas nas escolas médicas não sejam um fato novo, mas tenham existido sempre e tenham sido vividas pelos atuais professores quando eram estudantes. Frutos de instituições altamente hierarquizadas e, muitas vezes, violentas em suas relações, professores, preceptores e alunos foram, todos eles, mordidos/vampirizados e nada fazem hoje além de manter o ciclo de vampirização/violência. As condições de trabalho dos docentes nas escolas médicas têm se mostrado bastante insatisfatórias ${ }^{28,29}$, o que, embora não justifique o modo como se estruturam as relações humanas na instituição, decerto não contribuem para o melhor ambiente de ensino.

Outro aspecto do mito que deve ser lembrado é a imortalidade, um tema especialmente caro aos médicos, desde o mito fundador de Asclépio. Na mitologia grega, quando Asclépio passou a vencer a morte, ressuscitando os vivos, enfureceu os deuses e recebeu destes um castigo, que o colocava no devido lugar de humano, ainda que fosse um brilhante curador ${ }^{30}$.
Vencer a morte é ainda uma das motivações inconscientes que atrai os jovens alunos para a carreira médica ${ }^{31}$.

Vampiros são ainda descritos como criaturas não vivas ou mortos-vivos, seres que não sentem. Parte do processo que ocorre com os estudantes no trote tem este aspecto de dissociação ou alheamento do sofrimento do outro. Deste modo, quando alguns estudantes descrevem o trote do outro, não lhes parece violento, parecendo haver um consentimento. No entanto, quando trata de lidar com o trote sofrido por ele próprio, entra em contato com sentimentos de raiva, frustração e impotência, vividos outrora ${ }^{9}$. Esta alienação do sofrimento do outro pode não se restringir às relações com os pares e os superiores, mas contaminar a relação com os pacientes, diminuindo a empatia. Como descrito por Abuchaim ${ }^{32}$ :

Cada um de nós, estudantes de Medicina, quando veio à escola, trouxe acalentado seu desejo e suas fantasias do que pretendia e seria como médico. E o primeiro impacto oferecido a esse rasgo de idealismo potencial dos estudantes é jogá-los sobre um cadáver. Exatamente o oposto do que vieram buscar e, o que é mais dramático, é que, na maioria das vezes, esses alunos, pelo resto de sua existência, passarão buscando o cadáver imobilizado da Anatomia. Então, o paciente não tem sentimentos, não ama, não chora, não sofre.

\section{CONSIDERAÇÕES FINAIS}

Somado tudo, não se trata de propor que os estudantes e professores peguem estacas e saiam pelos corredores das escolas médicas atravessando o tórax uns dos outros. Tampouco não se trata de apenas insistir na proibição do trote, atuando ou tentando atuar em apenas um elo da possível cadeia causal. Em vez disto, é necessário refletir sobre os processos relacionais que existem nas instituições formadoras para que, compreendendo sua montagem, se possa caminhar para outras formas de iniciação mais sintônicas com o perfil do profissional que se pretende formar. Assim como no mito, para lidar com o problema é importante que este seja trazido à luz, identificando a ocorrência do abuso, examinando as formas como a instituição tem lidado com ele, e, em especial, que se encare criticamente a naturalização de algumas formas de violência nas escolas médicas.

Conta a lenda que, para ser mordida, a vítima deve convidar o vampiro a entrar em sua residência. É inegável que aspectos como o fascínio e a sedução pelo poder têm um peso na determinação da "abertura da porta" e do desejo de ter o poder de submeter o outro. Alunos que "fecham a porta" ao trote têm sido excluídos, não sendo considerados parte do grupo, 
pois "não aguentam nada". É importante estimular a empatia, ampliando espaços de humanização e troca nas relações entre calouros/veteranos/docentes. Para ser vampirizada irreversivelmente, a vítima deve ser mordida no mínimo três vezes. Ao longo de seis anos, quantas vezes colegas, residentes e docentes temos mordido uns aos outros, condenando a eles e a nós mesmos a viver nas sombras?

\section{AGRADECIMENTOS}

A autora agradece à FUNDUNESP que possibilitou a apresentação do trabalho no 49ํㅡㄹ Congresso de Educação Médica, ao CNPq pela bolsa de produtividade e ao Prof. José Luiz Aidar Prado pelas sugestões de leitura e a escuta atenta sobre as idéias que deram origem ao estudo.

\section{REFERÊNCIAS}

1. Nava P. Chão de Ferro. Rio de Janeiro: Ed José Olympio; 1976.

2. Vasconcelos PD. A violência no escárnio do trote tradicional. Um estudo filosófico em antropologia cultural. Santa Maria: Imprensa Universitária; 1993.

3. Warth MPT, Lisboa LF. Trote, Tradição e Violência. Interface comum saúde educ.1999;5:111-118.

4. Van Gennep A. Os ritos de passagem. Petrópolis: Ed Vozes; 1978.

5. Rodolpho AL. Rituais, ritos de passagem e iniciação: uma revisão da bibliografia antropológica. Estudos Teológicos. 2004;44(2):138-146.

6. Gomes P, Taffarel A. Depois do trote. Caderno Fovest. Folha de São Paulo, São Paulo, 2011 fev 16; p.4-6.

7. Akerman M, Conchão S, Hotimsky S, Boaretto R. Violência e Intimidação na recepção aos calouros nas faculdades de medicina: ato que persiste ao longo do ano. Rev Bras Educ Méd. 2010;34(4):627-628.

8. Meira MBV. Sobre estruturas etárias e ritos de passagem. Ponto e vírgula. 2009;5:185-201.

9. Villaça FM, Palácios M. Concepções sobre Assédio moral: bullying e trote em uma escola médica. Rev Bras Educ Méd. 2010;34(4):506-514.

10. Silver HK. Medical Students and Medical School. JAMA. 1982;247(3):309-310.

11. Frank E, Carrera JS, Stratton T, Bickel J, Nora LM. Experiences of belittlement and harassment and their correlates among medical students in the United States: longitudinal survey. BMJ. 2006; 333(7570):682.

12. Nagata-Kobayashi $S$, Sekimoto M, Koyama H, Yamamoto W, Goto E, Fukushima O. Medical Student Abuse during clinical clerkships. J Gen Intern Med. 2006;21:212-218.
13. Palácios M, Rego S. Bullying: mais uma epidemia invisível? (editorial). Rev Bras Educ Méd. 2006;30(1):3-5.

14. Rego S. A formação ética dos médicos: saindo da adolescência com a vida (dos outros) nas mãos. Rio de Janeiro: Editora Fiocruz; 2005.

15. Nicholson S. Helping to break the cycle of abused medical students becoming abusing teachers. BMJ. 2002;325:S47.

16. Uhari M, Kokkonen J, Nuutinem M, Vainionpaa L, Rantala H, Lautala P. Medical Student Abuse: an international phenomenon. JAMA. 1994;271(13):1049-1051.

17. Costa LSM, Pereira CAA. O abuso como causa evitável de estresse entre estudantes de medicina. Rev Bras Educ Méd. 2005;29(3):185-190

18. Azevedo VF, Knopholz J, Anacleto CR, Tano AL, Brasil FC, Elias ACZ. Humilhação, maus-tratos e discriminação de acadêmicos por preceptores e professores: estudo de caso. Rev Bras Educ Méd. 2002;26(1):119.

19. Ertem IG, Leventhal JM, Dobbs S. Intergenerational continuity of child physical abuse: how good is the evidence? Lancet. 2000;356:814-819.

20. Cukier R. Como sobrevivem emocionalmente os seres humanos. Rev Bras Psicodrama. 1995;3(11):59-78.

21. Bütz MR. The vampire as a metaphor for working with childhood abuse. American Orthopsychiatric Association. 1993;63(3):426-431.

22. Aidar JL, Maciel M. O que é Vampiro? São Paulo: Ed Brasileiense; 1986. [Coleção Primeiros Passos].

23. Lecouteux C. História dos vampiros. Autópsia de um mito. São Paulo: Editora UNESP; 2003.

24. Sledzik PS, Bellantoni N. Brief communication: bioarcheological and biocultural evidence for the New England Vampire Folk Belief. Am J Physical Anthropology.1994;94:269-274.

25. Prins H. Vampirism: A clinical condition. Br J Psych. 1985;146:666-668.

26. La Sierra LR. O Vampiro. Psicorama. 1990;2:25-29.

27. Ramos-Cerqueira ATA, Lima MCPL. A formação da identidade do medico: implicações para o ensino de graduação em medicina. Interface comun saúde educ. 2002;6:107-116.

28. Méis L, Velloso A, Lannes D, Carmo MS, Méis C. The growing competition in Brazilian science: rites of passage, stress and burnout. Brazilian Journal of Medical and Biological Research. 2003;36:1135-1141.

29. Souza FOC, Naujorks MI. O professor de medicina da UFSM no contexto do mal-estar docente. Rev Bras Educ Méd. 2005;29(1):34-40.

30. Cassorla R. O mito de Asclépios e o médico lidando com a morte. Cadernos do IFAN - Temas de Bioética. 1995;10:15-62. 
31. Rocco RP. Relação estudante de medicina-paciente. In: Mello Filho, J. Psicossomática hoje. Porto Alegre: Artes Médicas; 1992. p.45-56.

32. Abuchaim D. Uma experiência de ensino de psicologia médica e psiquiatria. J Bras Psiquiatr. 1980;29:127-133.

\section{CONFLITO DE INTERESSES}

Declarou não haver

\section{ENDEREÇO PARA CORRESPONDÊNCIA}

Maria Cristina Pereira Lima

Depto Neurologia, Psicologia e Psiquiatria

Faculdade de Medicina de Botucatu — UNESP — C.P. 540

Botucatu, São Paulo - SP

CEP: 18618-970

Email: mclima@fmb.unesp.br 